\title{
A consciência e o mundo na fenomenologia de Husserl: influxos e impactos sobre as ciências humanas
}

\section{Consciousness and the world in Husserl's phenomenology: influences and impacts on the human sciences}

\section{Carlos Diógenes Côrtes Tourinho*}

Universidade Federal Fluminense - UFF, Niterói, Rio de Janeiro, Brasil

\begin{abstract}
RESUMO
O presente artigo busca, inicialmente, esclarecer o problema fenomenológico da relação entre a consciência e o mundo. A fenomenologia de E. Husserl adota, do ponto de vista metodológico, a suspensão do juízo em relação à posição de existência do mundo, para recuperá-lo, na consciência, de modo indubitável, na sua pura significação. $O$ artigo procura esclarecer a especificidade da atitude fenomenológica, bem como da estratégia metodológica adotada pela fenomenologia para fazer da filosofia uma "ciência rigorosa". O artigo aborda ainda a crítica da fenomenologia à visão positivista nas ciências humanas. Se a adoção do programa positivista nas ciências humanas limita-nos à uma lógica indutiva e probabilística, o método fenomenológico nas ciências humanas convida-nos a exercer uma atitude reflexiva e analítica acerca do que há de mais originário na coisa sobre a qual retornamos.

Palavras-chave: Consciência, Mundo, Fenomenologia, E. Husserl, Ciências
\end{abstract} humanas.

\begin{abstract}
The present paper has as objective clarify the phenomenological problem of the relation between the consciousness and the world. The phenomenology of $E$. Husserl adopts of a methodological point of view the suspension of the judgement in relation to the position of the world's existence, recovering it in the consciousness, in an indubitable way, in his pure meaning. The paper tries to explain the specificity of the phenomenological attitude and the methodological strategy adopted by the phenomenology to do of philosophy a "rigorous science". The article also discusses the critical of the phenomenology to positivist view in the human sciences. The adoption of the positivist program in the human sciences limits us to an inductive and probabilistic logic, while the phenomenological method in the human sciences invites us to exercise a reflective and analytical attitude about what is most essential in the thing on which we return.
\end{abstract}

Keywords: Consciousness, World, Phenomenology, E. Husserl, Human sciences. 


\section{Introdução}

O presente artigo concentra-se, inicialmente, em torno da tarefa de aclarar a especificidade da atitude fenomenológica (enquanto modo de consideração do mundo), bem como da estratégia metodológica adotada pela fenomenologia de Edmund Husserl para o alcance de um grau máximo de evidenciação dos fenômenos. Tal atitude consiste, conforme será destacado, em uma atitude reflexiva e analítica, a partir da qual se busca, fundamentalmente, elucidar, determinar e distinguir o sentido íntimo das coisas (a coisa em sua "doação originária", revelada "em pessoa"), bem como as diferentes modalidades do aparecer enquanto tal. Já o método fenomenológico será, por sua vez, um método de evidenciação dos fenômenos, cuja estratégia consiste, grosso modo, no exercício da suspensão de juízo em relação à posição de existência das coisas, viabilizando a recuperação das mesmas em sua pura significação. Contrastando a atitude fenomenológica com o que Husserl chamou de "atitude natural" (modo de orientação no qual se encontra mergulhada a consciência das ciências positivas), o artigo abordará, em seguida, a crítica da fenomenologia à perspectiva positivista nas Ciências Humanas.

Enquanto o programa positivista deixa-nos, para o estudo do homem, confinados, do ponto de vista metodológico, a uma lógica indutiva, segundo a qual conhecer consiste em descrever, pela observação positiva dos fatos, a regularidade desses fatos, a abordagem fenomenológica nas ciências humanas convida-nos para uma clarificação do que há de mais fundamental na coisa sobre a qual retornamos, deslocando-nos a atenção dos fatos contingentes para o seu sentido originário indissociável de uma vivência intencional.

Tal abordagem consolida, com isso, uma espécie de "conversão filosófica" que nos faz passar de uma visão ingênua do mundo para um modo de consideração das coisas, no qual o mundo se revela em sua totalidade como "fenômeno".

\section{A filosofia como ciência de rigor: a orientação fenomenológica e a estratégia metodológica adotada pela fenomenologia de Husserl}

Pode-se dizer que, no século $X X$, o projeto filosófico anunciado por Husserl sob o nome de "fenomenologia transcendental" é, das Investigações Lógicas à Crise das Ciências Européias, movido e articulado desde o seu começo pela intenção primária de constituir a filosofia como uma "Ciência de Rigor", ambição que segundo o próprio autor acompanha a filosofia desde as suas origens (HUSSERL, [1911]1989). Fradique Morujão lembra-nos que, para Husserl, talvez 
não haja outra idéia tão poderosa, mais continuamente progressiva em toda a vida moderna, do que a idéia da "ciência". "Por isso, a filosofia, se quer manter os títulos de poder satisfazer as mais altas aspirações do espírito, deve constituir-se como ciência rigorosa" (Fradique Morujão, 2002, p. 149).

O ideal husserliano exprime-se pela determinação em dar uma fundamentação rigorosa à filosofia e, através dela, a todas as demais ciências. Tomado por sua ânsia de rigor absoluto, por um ímpeto próprio de sua formação matemática, Husserl encontrava-se, nas primeiras décadas do século $X X$, convencido de que a fundamentação da filosofia deveria implicar necessariamente em uma plena racionalidade da mesma, em uma clarificação do sentido íntimo das coisas por meio de uma reflexividade radical que daria consistência à própria filosofia. Husserl não se contentaria, a partir de então, com coisa alguma que não se revelasse em seu sentido próprio à consciência como um dado absolutamente evidente (para usar uma expressão sua, que não se revelasse "em pessoa"), mantendo-se, com isso, fiel ao propósito de garantir não o rigor ao modo das ciências ditas "positivas" (o rigor do método experimental), mas sim, o rigor absoluto necessário à pretensão de fundamentação do saber filosófico a partir do que é suscetível de ser conhecido de modo originário.

Isto porque a explicação empírica não poderia, apoiada na observação sistematizada e na descrição da regularidade dos fatos naturais, servir de fundamento último para este saber. Partia-se, então, da idéia de que para fazer da filosofia uma ciência rigorosa, para construir uma filosofia livre de todas as divergências, livre da ameaça de um ceticismo que, segundo Husserl, seria nocivo à própria filosofia, fazia-se necessário alicerçar a filosofia sob bases sólidas, apoiando-a em evidências absolutas (ou apodíticas), ou seja, em uma "ausência absoluta de dúvida" (absolute Zeifellosigkeit). De certo modo, fora já este o ideal de Descartes no século XVII: o de não admitir coisa alguma como verdadeira sem conhecê-la evidentemente como tal. Trata-se, na parte II do Discurso do Método, da chamada "regra da evidência" (DESCARTES, [1637] 1967, p. 47). O fim e o impulso do projeto filosófico husserliano encontram-se, portanto, intimamente determinados pela filosofia cartesiana, o que faz da fenomenologia uma espécie de "herdeira da modernidade" em pleno século $\mathrm{XX}$, herdeira de um ethos dominante na filosofia moderna.

Nos termos de Husserl, "poder-se-ía quase chamá-la um neocartasianismo..." (HUSSERL, 1931, p. 1). A filosofia é, para Husserl, a ciência que deve partir de fundamentos últimos ou, o que é o mesmo, de uma responsabilidade última indissociável de um espírito de radicalismo (como aquele manifestado nas Meditações cartesianas), de uma "vitalidade primitiva", cujo ímpeto não perde de vista as evidências últimas, encontrando nelas próprias a sua justificativa 
absoluta.

A intenção primária de constituir a filosofia como uma "ciência de rigor" é, portanto, em Husserl, a expressão do anseio maior que moverá, nas primeiras décadas do século $X X$, os rumos da fenomenologia. Vê-se, claramente, um esforço continuado de Husserl em retomar, em suas principais obras, a discussão acerca dos fundamentos da filosofia e, por conseguinte, das demais ciências. Afinal, o diagnóstico de Husserl sobre o seu tempo era o de que o começo do século XX anunciava, de certo modo, com a expansão de uma abordagem naturalista (tanto nas ciências naturais como nas ciências do espírito), um quadro crescente de crise na filosofia que, por sua vez, implicaria diretamente em uma crise de seus fundamentos. A ênfase neste ideal de uma fundamentação absoluta para a filosofia busca, conforme destacado, uma forte inspiração no projeto da filosofia cartesiana do século XVII (reforma total da filosofia para fazer desta uma ciência de fundamentos absolutos), cujo contexto também era de crise, marcado pela redescoberta do ceticismo antigo e por uma atmosfera de dúvidas e de incertezas.

No § 2 de Meditações Cartesianas, Husserl afirma-nos que: "Desenvolveremos as nossas meditações dum modo cartesiano, como filósofos que principiam pelos fundamentos mais radicais..." (HUSSERL, 1931, p. 5). Husserl busca em Descartes esta inspiração. Porém faz-se necessário ressaltar que a radicalização da qual resultou a fenomenologia transcendental apenas se tornou possível a partir de uma certa superação da filosofia cartesiana, ou como prefere Husserl: "....devido a um desenvolvimento radical de temas cartesianos" (HUSSERL, 1931, p. 21). Afinal, era preciso ir além da certeza do cogito, da chamada "evidência da cogitatio", do que Descartes apenas intuiu sem, no entanto, adentrar, deixando de explorar as "riquezas" de sua grande descoberta, não apreendendo o verdadeiro sentido e, consequentemente, não ultrapassando os portais da genuína filosofia transcendental. Daí o próprio Husserl comparar humorísticamente Descartes a Colombo:

também este fez uma grande descoberta - a descoberta dum novo continente, mas não penetrou no alcance dela, pois julgou ter descoberto apenas um novo caminho da velha India (HUSSERL, [1924] 1970, p. 340).

À fenomenologia caberia, portanto, promover impetuosamente uma investigação rigorosa do imenso campo da subjetividade transcendental.

Movido por seu projeto filosófico, Husserl anuncia-nos explicitamente - em A Idéia da Fenomenologia, núcleo das "Cinco Lições" proferidas em abril-maio de 1907 - que, com a fenomenologia, deparamo-nos com a proposta de uma "nova atitude" e de um "novo método". A 
atitude fenomenológica consiste em uma atitude reflexiva e analítica, a partir da qual se busca fundamentalmente elucidar, determinar e distinguir o sentido íntimo das coisas, a coisa em sua "doação originária", tal como se mostra à consciência. Trata-se de descrevê-la enquanto objeto de pensamento. Analisar o seu sentido atualizado no ato de pensar, explicitando intuitivamente as significações que se encontram ali virtualmente implicadas em cogitos inatuais, bem como os seus diferentes modos de aparecimento na própria consciência intencional. Explorar a riqueza deste universo de significações que a coisa - enquanto um cogitatum - nos revela no ato intencional é o que é próprio da atitude fenomenológica, enquanto um "discernimento reflexivo" levado a cabo com rigor. A especificidade de tal atitude faz da fenomenologia a "ciência clarificadora" por excelência. Já o método fenomenológico será, por sua vez, um método de evidenciação plena dos fenômenos. Também será, para Husserl, o método especificamente filosófico, cuja estratégia maior consiste, para o alcance de um grau máximo de evidência, no exercício da suspensão de juízo em relação à posição de existência das coisas. Tal exercício viabiliza, assim, a chamada "redução fenomenológica" e, com ela, a recuperação das coisas em sua pura significação, tal como se revelam (ou se mostram), enquanto objetos de pensamento, na consciência intencional.

O ponto de partida de Husserl é o que ele próprio definiu como sendo a "Tese do Mundo", isto é, a tese segundo a qual o que chamamos de "mundo" encontra-se aí, diante de nós, tudo isto que, da maneira a mais imediata e direta, nos é revelado através da experiência sensível: as coisas situadas em uma dimensão espaço-temporal, cada uma das quais com as suas propriedades, relações, etc. Trata-se do mundo que nos cerca, constituído de entes mundanos, frente aos quais podemos tomar atitudes variadas, quer nos ocupemos com eles quer não. Vivenciamos, portanto, a todo instante, a chamada "Tese do Mundo". Mas, se além da vivência dessa tese, fazemos uso da mesma, passamos, então, a exercer o que Husserl chamou de "atitude natural" (natürliche Einstellung), atitude por meio da qual atribuo a mim um corpo em meio a outros corpos e me insiro no mundo através da experiência sensível, "...num mundo de coisas que se estende 'perante o meu olhar' no espaço e no tempo...Descubrome a mim mesmo como 'ser-no-mundo'" (KELKEL L., A.; SCHÉRER, 1982 , p. 41). Admito, em tal atitude, sem que haja, ao menos, um exame crítico, a posição de existência do mundo (concebido como "realidade factual"), bem como a possibilidade de conhecê-lo e, com isso, adoto, de certo modo, um "realismo ingênuo". Nos termos de Kelkel \& Schérer: "A atitude natural da consciência colocada no mundo caracteriza-se, precisamente, pela fé ingênua na realidade e na permanência do mundo percepcionado" (KELKEL L., A.; SCHÉRER, 1982, p. 41). Neste sentido, a tarefa crítica da Teoria do 
Conhecimento de promover uma investigação acerca do que torna possível a relação de correspondência entre as vivências cognoscitivas e as coisas a serem conhecidas encontra-se desapercebida na atitude natural. Dá-se às costas para o chamado "enigma do conhecimento transcendente", para o que, classicamente, passou-se a chamar pelo nome de "problema da correspondência". Afinal, o que torna possível tal conhecimento do mundo? Em que ele se funda? Quais são os seus limites? Dá-se, portanto, na atitude natural, a possibilidade do conhecimento do mundo - entendido como "realidade factual" - como algo certo e inquestionável. Para Husserl, tanto a consciência do senso comum quanto a consciência das ciências ditas "positivas" encontram-se, ainda que de modos distintos, mergulhadas na atitude natural, cujo exercício expressa a relação entre uma consciência espontânea (empírica ou psicológica) e o mundo natural, revelado empiricamente para essa consciência em sua facticidade.

Fiel ao seu projeto filosófico de constituição da filosofia como uma "Ciência de Rigor", Husserl sabe que as tais evidências apodíticas necessárias para a fundamentação da própria filosofia - não poderiam ser extraídas do plano empírico-natural, pois, por mais perfeita que seja uma percepção empírica, ela será sempre a percepção de um ponto de vista e, enquanto tal, somente poderá revelar "aspectos" ou "perspectivas" da coisa percebida que, por sua vez, não será revelada em sua plenitude, mas apenas parcialmente. Ainda assim, a crença acerca do que percebemos empiricamente vai muito além daquilo que a percepção empírica efetivamente nos revela. Neste sentido, pode-se dizer que a coisa vista empiricamente será sempre um "misto de visto e não visto". Portanto, toda evidência extraída do plano empírico-natural, no qual a consciência empírica se relaciona com as coisas mundanas, será sempre uma evidência perspectivista (ou existencial), ou seja, uma evidência parcial. Como nos diz Husserl, dos fatos não podemos extrair "evidências absolutas" (a coisa e o mundo em geral não são apodíticos, pois não excluem a possibilidade de que duvidemos deles e, portanto, não excluem a possibilidade de sua não existência). Eis um segundo motivo do porque não podermos, na visão de Husserl, extrair evidências plenas de nossa percepção empírica do mundo, pois, a julgar pelo o que a experiência sensível nos revela do mundo, nós jamais poderíamos eliminar, por completo, a possibilidade de duvidar da posição de existência das coisas que se nos apresentam e, neste sentido, estaríamos sempre prestes a corrigir as nossas percepções do que havia sido estabelecido com base na experiência sensível. Portanto, para Husserl, com base no ente mundano, seria impossível elaborar uma filosofia que se pudesse apresentar como ciência rigorosa.

Como estratégia metodológica para 0 alcance das evidências apodíticas, condição para a fundamentação da filosofia como "ciência 
rigorosa", Husserl opta pelo exercício da epoché, isto é, pelo exercício da "suspensão de juízo" em relação à posição de existência das coisas.

Husserl recupera, já nas "Cinco Lições" e, posteriormente, em Idéias I, o conceito de epoché do ceticismo antigo, porém, para pensá-lo não como um modus vivendi (como um princípio ético a ser praticado como "hábito virtuoso") - conforme propunha o ceticismo pirrônico no período Helênico - mas sim, como um recurso metodológico. Com o exercício da epoché, abstemo-nos de tecer considerações acerca da existência ou não existência das coisas mundanas. Nos termos de Husserl, promovo a "colocação da atitude natural entre parênteses", a facticidade do mundo fica "fora de circuito". Ao suspender o juízo em relação à facticidade do mundo, eu não deixo de vivenciar a "tese do mundo", no entanto, como diz o § 31 de Idéias I, não faço mais uso dessa tese, procuro mantê-la fora de circuito: "...a tese é um vivido, mas dele não fazemos 'nenhum uso'..." (HUSSERL, [1913] 1950, p. 99).

Tal renúncia implica, de certo modo, em uma espécie de "conversão filosófica" e, por isso mesmo, como nos lebra Lauer, implica na aceitação de uma nova atitude por meio da qual o mundo ele mesmo nos é revelado, conforme veremos, em sua versão imanente (LAUER, 1954).

A serviço desta tal reflexividade radical própria da atitude fenomenológica, a epoché fenomenológica proporcionará, em seu exercício generalizado, o deslocamento da atenção, inicialmente voltada para os fatos contingentes do mundo natural, para o domínio de uma subjetividade transcendental, "...domínio absolutamente autônomo do ser puramente subjetivo..." (HUSSERL, [1924] 1970, p. 321 ), dentro do qual e a partir do qual os "fenômenos" - enquanto idealidades puras - se revelarão como "evidências absolutas" para uma consciência transcendental, dotada da capacidade de ver verdadeiramente estes fenômenos tal como se apresentam em sua plena evidência. Trata-se, como o próprio Husserl insiste em ressaltar, em diferentes momentos de sua obra, de um "puro ver" das coisas. Ainda nos termos do $\S 35$ de Idéias $I$, trata-se "...não exatamente e meramente do olhar físico, mas do 'olhar do espírito'..." (HUSSERL, [1913] 1950, p. 113).

Nas "Cinco Lições", Husserl nos diz: "A fenomenologia procede elucidando visualmente, determinando e distinguindo o sentido... Mas tudo no puro ver" (Husserl, [1907] 1997, p. 87). Em suma, a fenomenologia prescindirá de tecer considerações acerca da posição de existência das coisas mundanas para direcionar, então, a atenção para os "fenômenos", tal como se revelam (ou como se mostram), em sua pureza irrefutável, na auto-reflexão da consciência transcendental. Nos termos de Husserl, atingimos assim o "ego cogito" verdadeiramente radical, somente inteligível na sua 
explicitação plena "ego-cogito-cogitatum" (Husserl, 1931, pp. 28-32). Portanto, de um lado, deparamo-nos com um modo de consideração das coisas a partir do qual o mundo se revela para a nossa consciência espontânea como o domínio empírico-natural dos fatos, do que se encontra submetido a uma dimensão espaço-temporal. Trata-se do modo de consideração do mundo próprio das ciências positivas em geral. Paralelamente, como um recurso metodológico para o alcance das evidências apodíticas, o exercício generalizado da epoché $\mathrm{e}$, conseqüentemente, $\mathrm{da}$ redução fenomenológica, promoverá o salto para o modo de consideração transcendental (ou fenomenológico) das coisas, fazendo agora com que o mundo se revele, na e para a consciência pura (ou transcendental), como um "horizonte de sentidos". Se esta consciência pura não pode ser tomada em termos de dados empíricos, cabe-nos apenas concebê-la a partir de sua relação intencional com o seu objeto que, em sua versão reduzida, enquanto um objeto de pensamento, nada mais é do que um conteúdo intencional da consciência. Trata-se, com tal redução, de fazer o mundo reaparecer na consciência como um horizonte de idealidades meramente significativas, que se revelam como um dado absoluto e imediato para uma tal consciência pura que o apreende e o constitui intuitivamente. A mesma consciência que intuitivamente apreende o objeto em sua versão reduzida, isto é, como "fenômeno puro", é também responsável pela constituição desse mesmo objeto, agora atualizado no pensamento como uma unidade de sentido. $O$ objeto, precisamente porque inconcebível sem ser pensado, enquanto um cogitatum, exige uma doação de sentido que só pode vir através dos atos intencionais da consciência, isto é, as unidades de sentido pressupõem uma consciência doadora de sentido.

Portanto, deparamo-nos com duas atitudes - a "atitude natural" e a "atitude fenomenológica" - das quais decorrem dois modos distintos de consideração das coisas: se no primeiro modo de consideração, o mundo nos é revelado em sua facticidade, no segundo modo, o mundo se revela, na consciência transcendental, em sua pura significação, o que é o mesmo que dizer que o mundo se revela, em sua totalidade, como "fenômeno". Nesse sentido, pode-se dizer que o exercício generalizado da epoché - concebido como um recurso metodológico para o alcance de um grau máximo de evidenciação, ou como prefere Lauer, como "uma técnica de eliminação da dúvida inerente a toda posição do fáctico, do contingente" (LAUER, 1954, p. 173) - coloca-nos frente a frente com o que Husserl considerou a mais radical de todas as diferenciações ontológicas. De um lado, o ser como ser "transcendente" (o mundo exterior que transcende a consciência, mundo para o qual nos encontramos naturalmente orientados e sobre o qual a epoché será exercida) e, de outro, o ser como um dado imanente, presença absoluta, in-existindo sob o modo 
de "coisa pensada", apreendida e constituída intuitivamente na consciência transcendental. A fenomenologia transcendental será, então, uma fenomenologia da consciência constituinte (pode-se dizer que, em Husserl, "ser evidente é ser constituído"). Exercer a epoché é reduzir à consciência transcendental. Tal redução do objeto à consciência transcendental, na medida em que não desfaz a relação entre sujeito e objeto, revela uma dimensão nova dessa relação, impedindo que a verdadeira e autêntica objetividade desapareça.

\section{A crítica de Husserl à orientação positivista nas ciências humanas: indução $X$ intuição de essências}

Quando pensamos a crítica da fenomenologia às ciências positivas, pensamos, então, em dois modos distintos de consideração do mundo. A crítica da fenomenologia ao modo de consideração positivista se faz notar, particularmente, quando colocamos frente a frente o exercício do método indutivo adotado pelas ciências positivas com o que Husserl chamou de "intuição de essências" (Wesenschau). $\mathrm{Na}$ investigação fenomenológica, tal "intuição de essências" surge como a visão por meio da qual a coisa intencionada nos é revelada em sua doação originária e, portanto, em um grau apodítico de evidenciação. Toda ciência pressupõe, segundo Husserl, um quadro de essências. Porém, ao tomar o fato como objeto de uma observação sistematizada, procurando descrever a sua regularidade, o cientista positivista desconhece o quadro de essências que a sua investigação pressupõe, almejando, com o exercício da indução, inferir uma "lei geral". Para Husserl, tal lei inferida nada mais é do que uma generalização, cuja validade é meramente empírica ou circunstancial (HUSSERL, [1900] 1959, § 21).

Em um processo inverso aquele adotado pelo programa positivista, a investigação fenomenológica esforça-se em promover uma reflexão levada a cabo com rigor e discernimento acerca do que seja propriamente a coisa investigada. Antes de se levar adiante uma investigação na ciência física, por exemplo, faz-se necessário refletir sobre o que seja a "coisa física" em sua essência. O próprio Husserl salienta, em sua Crise das Ciências Européias, que Galileu já havia estabelecido uma eidética da coisa física, de modo que não poderia obter a lei da queda dos corpos induzindo o universal a partir do diverso da experiência, mas somente pela "intuição de essência" do corpo físico. O mesmo raciocínio valeria para as demais ciências, de modo que, para cada ciência empírica corresponderia, segundo Husserl, uma ciência eidética concernente ao eidos regional dos objetos adotados para investigação.

Com a fenomenologia, deparamo-nos, de antemão, com uma eidética, isto é, com uma "doutrina de essências". Para Husserl, não 
há ciência que não comece por estabelecer um quadro de essências obtidas pela chamada "técnica de variação imaginária dos objetos". A variação arbitrária de um objeto qualquer na imaginação permite-nos notar que tal arbitrariedade não pode ser completa, uma vez que há condições necessárias sem as quais as "variações" deixam de ser variações daquilo que se intenciona no pensamento. Cada uma dessas possibilidades ou desses "exemplares" que se perfilam - "...de uma maneira inteiramente livre, ao sabor da nossa fantasia..." (HUSSERL, 1931, p. 59) - na imaginação somente poderá variar enquanto variação daquilo que se intenciona em um cogito atual, na medida em que necessariamente tais variações compartilham algo de "invariante", coincidindo em relação ao caráter necessário do que é intencionado no próprio pensamento.

Nos termos de Husserl, no $\S 98$ de Lógica Formal e Lógica Transcendental, tratam-se de "divergências que se prestam à coincidência" (HUSSERL, [1929] 1965, p. 33). Trata-se, portanto, de uma "condição necessária" sem a qual não poderíamos exercer as referidas variações, sem a qual sequer poderíamos considerar no pensamento um determinado objeto intencionado como tal. Tal "núcleo invariante" do cogitatum - o caráter necessário do objeto idealmente considerado - define precisamente a "essência" daquilo que se mostra na e para a consciência intencional, revelando-se, portanto, em sua dimensão originária na própria intuição vivida. Eis o que Husserl denominou de "intuição de essências" (Wesenschau). A essência se experimenta, então, em uma intuição vivida. Cabe notar que, em Husserl, conforme nos lembra Lyotard:

\footnotetext{
...a "visão de essências" não tem nenhuma característica metafísica, a teoria das essências não se enquadra em um realismo platônico onde a existência de essências seria afirmada, a essência é somente esta em que a "coisa mesma" me é revelada em uma doação originária (LYOTARD, [1954] 2004, p. 12).
}

A "essência" deve ser, então, entendida em Husserl não como uma "forma pura" que subsiste por si mesma, independentemente do modo como se mostra à consciência intencional, mas sim, como o que é retido no pensamento pela referida técnica de variação imaginária: atenho-me, ao exercer a redução fenomenológica, ao núcleo invariante da coisa, isto é, ao que persiste na coisa pensada mesmo diante de todas as variações as quais a submeto arbitrariamente em minha imaginação.

No § 34 de Meditações Cartesianas, Husserl descreve-nos novamente a dinâmica do exercício da variação imaginária dos objetos na consciência, afirmando-nos que tal exercício permite-nos deslocar a atenção das variações as quais submeto arbitrariamente o objeto intencionado para a sua "generalidade essencial" e absoluta, 
generalidade essencialmente necessária para qualquer caso particular desse mesmo objeto (HUSSERL, 1931, p. 59/60).

Pode-se dizer que a investigação de essências (Wesensforschung) se torna uma peça decisiva quando nos referimos a uma abordagem fenomenológica das ciências. No caso das ciências do homem, Lyotard mostra-nos que, adotando, por exemplo, tal abordagem na sociologia, se quisermos investigar a existência de uma instituição em um determinado grupo social, sua gênese histórica e o seu papel atual na sociedade, faz-se necessário definir, primeiramente, pela variação imaginária, o que seja esta instituição (LYOTARD, [1954] 2004). Se tomarmos a sociologia de Durkheim como exemplo, constataremos que a mesma assimila a vida religiosa à experiência do sagrado, afirmando-nos que o sagrado tem a sua origem no totemismo, cuja origem resulta, por sua vez, de uma sublimação do social. No entanto, é exatamente neste ponto que uma visada fenomenológica da sociologia poderia promover os seguintes questionamentos: a experiência do sagrado constitui a essência da vida religiosa? Não seria possível conceber (por variações imaginárias) uma religião que não se apoiasse sobre esta prática do sagrado? Enfim, o que significa o "sagrado" propriamente dito? Ao invés de inferir regras gerais a partir da observação de casos particulares e da descrição da regularidade desses casos, conforme propõe, do ponto de vista metodológico, o programa positivista, a atitude fenomenológica concentra-se - em um processo inverso aquele adotado pelas ciências positivas - na descrição (ou análise) de essências. Nos termos de Husserl, trata-se, com a atitude fenomenológica, de um processo dinâmico, de uma atitude reflexiva e analítica, cujo intuito central passa a ser o de promover a elucidação do sentido originário que a coisa expressa, em sua versão reduzida, independentemente da sua posição de existência.

Engana-se aquele que pensa que, com a estratégia metodológica, adotada pela fenomenologia, Husserl estaria negando a existência do mundo. Antes sim, estaria renunciando a um modo ingênuo de consideração do mesmo, para viabilizar, com o exercício da redução fenomenológica, o acesso a um modo transcendental de consideração do mundo. Afinal, como nos lembra Merleau-Ponty, "o filósofo, enquanto filósofo, não deve pensar à maneira do homem exterior, deste sujeito psicofísico que estaria no tempo, no espaço, na sociedade..." (MERLEAU-PONTY, [1951]1973, p. 22). Ao filósofo é necessário suspender o juízo acerca do conjunto de afirmações implicadas nos dados de fato de sua vida. "Suspendê-las, porém, não é negá-las, e, menos ainda, negar o vínculo que nos liga ao mundo físico, social e cultural; ao contrário, é vê-lo e ser dele consciente" (MERLEAU-PONTY, [1951]1973, p. 22).

Em sua versão reduzida, o mundo se abriria, então, enquanto campo fenomenal, na e para a consciência intencional como um "horizonte 
de sentidos". Sem negar a existência do mundo factual, renunciamos, pela epoché, à ingenuidade da atitude natural, para reter, então, a "alma do mundo", o mundo na sua pura significação. Conforme faz questão de destacar Júio Fragata (1956), citando o próprio Husserl, em um curso inédito proferido na Universidade de Göttingen, na Alemanha, em 1909:

\begin{abstract}
Perdemos o mundo, para o ganhar de um modo mais puro, retendo o seu sentido. A fenomenologia põe fora de circuito a realidade da natureza, mesmo a realidade do céu e da terra, dos homens e dos animais, do próprio eu e do eu alheio, mas retém, por assim dizer, a alma, o sentido de tudo isso com o qual estou imediatamente em contato, de modo que os objetos assim considerados não só estão presentes diante de mim, mas brotam de mim mesmo (FRAGATA, 1956, p. 113).
\end{abstract}

A redução fenomenológica faz reaparecer, na própria camada intencional do vivido, a verdadeira objetividade pela qual o objeto intencionado é, enquanto conteúdo intencional do pensamento, constituído e apreendido intuitivamente. Daí o próprio Husserl dizer, em Idéias diretrizes para uma Fenomenologia (1913), que se por "positivismo" entendemos o esforço de fundar as ciências sobre o que é suscetível de ser conhecido de modo originário, nós é quem somos os verdadeiros positivistas! (HUSSERL, [1913] 1950, p. 69) Se as ciências positivas não deixam de conceber a relação entre subjetivo e objetivo em termos da dicotomia "interioridade" / "exterioridade", considerando o objetivo como algo que nos remete sempre para uma realidade exterior e independente, para o que transcende a própria vivência do mundo, a redução fenomenológica permite-nos, ao nos lançar para o modo transcendental de consideração do mundo, recuperar a autêntica objetividade na própria subjetividade transcendental - domínio último e apoditicamente certo sobre o qual deve ser, segundo Husserl, fundada toda e qualquer filosofia radical unindo, com isso, o objetivo e o subjetivo. Trata-se, nos termos de Husserl, em suas Conferências de Paris, em 1929, de "...uma exterioridade objetiva na pura interioridade" (HUSSERL, [1929] 1992, p. 11), unindo, com isso, o objetivo e o subjetivo.

\title{
4 Conclusão
}

A adoção do programa positivista nas ciências humanas implica, ao fazer uso da Tese do Mundo, ao mergulhar a consciência na atitude natural, na aceitação de um realismo ingênuo (isto é, na aceitação do mundo como uma "realidade de fatos", acerca da qual o conhecimento se torna uma possibilidade inquestionável), desconsiderando, nesse sentido, os problemas filosóficos suscitados 
pela Teoria do Conhecimento, tais como: o que torna possível tal conhecimento do mundo? Em que ele se funda? Quais são os seus limites? Este mesmo programa insiste, nos estudos sobre o homem (seja em Sociologia, seja em Psicologia), em inferir generalizações empíricas a partir da observação sistematizada do comportamento humano, desenvolvendo um estudo periférico do homem em relação ao meio no qual se encontra inserido. Particularmente, em Psicologia, a aceitação do programa positivista começa a se consolidar no último quarto do século XIX por meio de uma aliança da ciência psicológica com o método experimental das ciências naturais. Tal aliança fez, no mesmo período, com que boa parte dos sistemas em psicologia incorressem no equívoco de confundir, na aceitação de um paralelismo psicofísico, as leis do pensamento com as leis causais da natureza (propondo inclusive uma espécie de "física do pensamento"), confundindo, com isso, o "sujeito do conhecimento" com o "sujeito psicológico", conforme o próprio Husserl denunciou em sua crítica ao psicologismo nos Prolegômenos das Investigações Lógicas. Tal programa positivista deixa-nos, para o estudo do homem, confinados, do ponto de vista metodológico, a uma lógica indutiva, segundo a qual conhecer consiste em descrever, pela observação positiva dos fatos, a regularidade desses fatos, buscando, a partir de casos particulares, inferir "leis gerais" que, por sua vez, não passam de "generalizações empíricas" e, como tais, não perdem o seu caráter "circunstancial", "episódico" e "probabilístico". Tais generalizações não são, portanto, "leis" no sentido genuíno, uma vez que não possuem um valor apodítico. Neste sentido, no exercício da indução, o positivista desconhece o quadro de essências acerca dos fatos que investiga. Já a abordagem fenomenológica nas ciências humanas convida-nos a exercer justamente uma reflexividade levada a cabo com rigor e discernimento acerca deste quadro de essências estabelecido por variações imaginárias, a recuperar a intuição originária daquilo que se toma como objeto de investigação. Convidanos, portanto, a uma atitude reflexiva e analítica acerca do "sentido íntimo" daquilo que se investiga - tanto aquele que se atualiza no pensamento quanto as significações que se encontram ali virtualmente presentes, bem como os seus diferentes modos de aparecimento na própria camada intencional do vivido.

Tal abordagem fenomenológica convida-nos, enfim, para uma clarificação do que há de mais fundamental na coisa sobre a qual retornamos, deslocando-nos a atenção dos fatos contingentes para o seu sentido originário indissociável de uma intencionalidade, consolidando, com isso, uma espécie de "conversão filosófica" que nos faz passar de uma visão ingênua do mundo para o "puro ver" das coisas, no qual o mundo se revela em sua totalidade como "fenômeno". Eis o convite genuíno da fenomenologia às ciências humanas. 


\section{Referências}

DESCARTES, R. Discours de la méthode. Paris: Hachette , ([1637] 1967).

FRADIQUE MORUJÃO, A. "Husserl e a filosofia como ciência rigorosa". In: Estudos filosóficos - Vol. 1. Lisboa: Imprensa Nacional Casa da Moeda, 2002.

FRAGATA SJ, J. A fenomenologia de Husserl como fundamento da filosofia. Braga: Livraria Cruz, 1956.

HUSSERL, E. Recherches logiques. Tome 1: Prolégomènes à la logique pure. Collection Epimethée. Paris: PUF, ([1900] 1959).

. L'idée de la phénoménologie. Cinq leçons. Collection Epimethée. Paris: PUF, ([1907] 1997).

. La philosophie comme science rigoureuse. Collection Epimethée. Paris: PUF, ([1911]1989).

Idées directrices pour une phénoménologie et une philosophie phénoménologique pures (Tome Premier). Paris: Gallimard, ([1913] 1950).

- Kant et I'idée de la Philosophie Transcendantale. In: Philosophie première 1923-1924, 1: Histoire critique des idées. Appendice. 3ed. Collection Epimethée. Paris: PUF, ([1924]1970), pp. 299-368.

1992).

Conferências de Paris. Lisboa: Edições 70, ([1929]

Logique Formelle et logique transcendantale. Paris:

Presses Universitaires de France, ([1929] 1965).

. Méditations Cartésiennes. Paris: Librairie Armand Colin,

1931.

La crise des sciences européennes et la

phénoménologie transcendantale. Paris: Gallimard, ([1936] 1989).

KELKEL L., A.; SCHÉRER, R. Husserl. Lisboa: Edições 70, 1982.

LAUER, Q. Phénoménologie de Husserl. Essai sur la Genèse de I'Intentionnalité. Paris: Presses Universitaires de France, 1954.

LYOTARD, J-F La phénoménologie. Que sais-je? Paris: PUF, ([1954] 2004).

MERLEAU-PONTY, M. Ciências do homem e fenomenologia. São Paulo: Edição Saraiva, ([1951]1973).

Endereço para correspondência

Carlos Diógenes Côrtes Tourinho

Universidade Federal Fluminense. Faculdade de Educação. Departamento de Fundamentos Pedagógicos (SFP) Campus do Gragoatá - Bloco D - $4^{\circ}$ andar - sala 403. Rua Professor Waldemar Freitas Reis, s/n CEP: 24.210201, Niterói, RJ, Brasil

Endereço eletrônico: cdctourinho@yahoo.com.br 
Recebido em: 20/10/2011

Reformulado em: 23/05/2012

Aceito para publicação em: 24/05/2012

Acompanhamento do processo editorial: Ana Maria Lopez Calvo de Feijoo

\section{Notas}

*Doutor em Filosofia pela PUC-Rio. Professor Adjunto de Filosofia da Faculdade de Educação da UFF. Professor do Programa de Pós-Graduação em Filosofia da UFF. Membro do GT de Filosofia Francesa Contemporânea e do GT de Fenomenologia da ANPOF. 